\title{
Evaluation of pro-inflammatory and anti-inflammatory cytokines in type 1 diabetes mellitus
}

\author{
Weaam Gouda', Lamiaa Mageed ${ }^{1}$ (D), Soha M. Abd El Dayem² (D), Esmat Ashour ${ }^{1 *}$ (D) and Mie Afify ${ }^{1}$ (B)
}

\begin{abstract}
Background: Type 1 diabetes mellitus (T1DM) is a chronic inflammatory disease concerning insulin-producing $\beta$-cells destroyed by the conjoined action of auto reactive T cells, inflammatory cytokines and monocytic cells. Recent proof favors crucial role of cellular autoimmunity as well as its mediators in pathogenesis and following T1DM. We aimed to investigate whether IL-1a, IL-1 $\beta$, or IL-10 an easily available inflammatory marker is associated with T1DM.

Results: The onset of T1DM was accompanied with elevation serum levels of IL-1a, IL-1 $\beta$, and IL-10. ROC curve revealed that IL10 $>5.95 \mathrm{pg} / \mathrm{ml}$ predicted T1DM with sensitivity and specificity of $96 \%$ and $90 \%$, respectively.

Conclusion: The raise of serum inflammatory cytokines such as IL-1a, IL-1 $\beta$, and IL-10 of the patient may be exploited as potential markers for development of T1DM. The study proposes that level of inflammatory markers is upregulated in T1DM individual in an age-dependent manner and suggesting activation of the inflammatory immune response system.
\end{abstract}

Keywords: Type 1 diabetes mellitus (T1DM), i Interleukin-1alpha (IL-1a), Interleukin-1 beta (IL-1ß), Interleukin-10 (IL-10)

\section{Background}

Type 1 diabetes mellitus (T1DM) is an autoimmune disease characterized as multifactorial disorders attributable to $T$ cell-mediated destruction of the pancreatic $\beta$ cells caused by interaction between inherited and ecological factors (Al-Terehi et al. 2016). It accounts for $80-90 \%$ in diabetic children and adolescents (Dabelea et al. 2014). The incidence of DM was 387 million in 2014, and a raise of approximately 205 million new cases is expected to occur by 2035 (International Diabetes Federation 2015). Some of the diabetic patients are asymptomatic particularly in children with absolute insulin insufficiency who may undergo polyphagia, polydipsia, polyuria, blurred vision, and weight loss. Uncontrolled diabetic individuals may cause stupor, coma, and ketoacidosis or non-ketotic hyperosmolar syndrome that may lead to death (Galtier 2010).

Cytokines are extracellular proteins of low molecular weight that act as immune response mediators. They perform in highly complex pathways that regulate the inflammatory process, and they are essential to conduct

\footnotetext{
* Correspondence: esmatashour3@gmail.com

${ }^{1}$ Biochemistry Department, National Research Centre, Giza, Egypt Full list of author information is available at the end of the article
}

response to the lesion site. Low-grade chronic inflammation and stimulation of the innate immune system are identified to be strongly linked to the pathogenesis of DM (Navarro-González and Mora-Fernández 2008). Pro and anti-inflammatory cytokines have been suggested to be implicated in the events of diabetes (Banerjee and Saxena 2014). Previous reports revealed that definite pro and/or anti-inflammatory cytokines are able to interfere with insulin responsive glucose uptake and stimulate insulin resistance ( $M$ and DR 2014).

Pro-inflammatory cytokines, interleukin-1alpha (IL-1 $\alpha)$, and interleukin-1beta (IL-1 $)$ are strong inflammatory inducers that could significantly relate to the pathogenesis of DM (Buraczynska et al. 2007). IL-1 is expressed early in the insulate infiltrate and may be regarded as a circulating biomarker of T1DM risk. The major IL-1 activities are performed by IL-1 $\beta$, which is released from producing cells through pathways as yet unclear, and IL- $1 \alpha$ that is either anchored in the plasma membrane or transported into the nucleus as a transcriptional coregulator (Dinarello et al. 2012). Interleukin-10 (IL-10) is an anti-inflammatory and immunosuppressive substance created inside the body and acting as a regulator of immune response (Moore et al. 2001). The release of IL-10 produces an efficient 
autocrine mechanism for controlling pro-inflammatory cytokine production when its expression was delayed (Kolla et al. 2009).

In the present study, we have tried to illustrate the relationship between pro-inflammatory and anti-inflammatory cytokines such as IL- $1 \alpha$, IL-1 $\beta$, and IL-10 which are simultaneously responsible for of T1D pathogenesis in children and adolescents below 25 years with varying duration of diabetes.

\section{Methods}

\section{Human subjects}

Between November 2015 and April 2016, T1D patients attending the Centre for Diabetes and Endocrinology, children hospital in Giza, were selected for the study. The study group consisted of 230 patients with type 1 diabetes patients (117 females and 114 males) diagnosed according to the criteria provided by American Diabetes Association. Exclusion criteria were set as follows: autoimmune diseases (e.g., rheumatoid arthritis), steroid therapy and macrovascular complications (e.g., myocardial infarction), any diabetic complications such as nephropathy, neuropathy, or retinopathy, and acute or chronic diseases. All the patients were newly diagnosed who later started taking regular insulin injections after first blood withdrawal for further follow-up study. Healthy age-matched individuals $(n=168)$ with no family history or clinical evidence of type 1 diabetes or any chronic diseases and obvious abnormalities served as controls. None of the diabetics were on any medication including aspirin, immunosuppressive medications, antibiotics, or anti-inflammatory drugs or other agents known to affect cytokine production.

\section{Laboratory and clinical data}

The background information of subjects such as age, gender, weight, height, daily dose of insulin injection, disease duration, and family history of diabetes were recorded. Disease duration was defined in this study as the day of initial diagnosis of diabetes to the day of blood collection.

Blood pressure was measured three times for patients and controls after 5-min rest in the sitting position on both upper limbs with the use of automatic manometer (Omron M4 Plus, Omron Health care Europe, Hoof drop, and Holland). The mean value of the second and the third measurement was calculated. The measurements taken on the dominant limb were analyzed.

Anthropometric measurements in the form of weight, height, waist circumference (WC), and hip circumference $(\mathrm{HC})$ were taken for each participant. The weight and height of the participants were measured up to $0.01 \mathrm{~kg}$ and $0.1 \mathrm{~cm}$ using a Seca Scale Standing Balance and a Holtain Portable Anthropometer (Holtain, Ltd., Crymmych, Wales, UK). Body mass index (BMI) was calculated as weight (in kilograms) divided by height (in meters) squared. Waist circumference was measured at the level of the umbilicus with the participant standing and breathing normally; hip circumference was measured at the level of the iliac crest, using non stretchable plastic tape to the nearest $0.1 \mathrm{~cm}$. The waist/hip ratio and waist/height ratio $(\mathrm{cm} / \mathrm{cm})$ were calculated. Each measurement was taken as the mean of three consecutive measurements, using standardized equipment (Tanner et al. 1969; Cameron 1986).

\section{Sample collection}

Five milliliters of venous blood were collected from each child under aseptic condition. It was left to clot for $15 \mathrm{~min}$, centrifuged, and serum was separated. Assessment of random blood sugar was done immediately, and the rest of the serum was used for determination of cytokines (IL-1 $\alpha$, IL-1 $\beta$, and IL-10) levels.

\section{Biochemical measurements}

Fasting blood glucose levels were measured with an enzymatic colorimetric method (Stanbio laboratory, USA). The levels of IL- $1 \alpha$, IL-1 $\beta$, and IL-10 were assayed by an enzyme-linked immunosorbent assay employing Human cytokine ELISA set (IBL International GmbH, Germany and Orgenium Laboratories' human, Vantaa Finland) respectively. ELISA was performed following the manufacturer's protocol.

\section{Statistical analysis}

Sample size calculation was done using Stats Direct statistical software version 2.8 for MS Windows, Stats Direct Ltd., Cheshire, UK. Analysis of data was done by IBM computer using SPSS (statistical program for social science version 20) (SPSS Inc., Chicago, IL, USA). Independent sample $t$ test was used for comparison between the two groups, and differences with a $p$ value $\leq 0.05$ were considered to be statistically significant. Correlations between different variables and the studied groups were analyzed using Spearman correlation test. Receiver-operating characteristic (ROC) analyses were used to compare the performance power of the IL-1 $\alpha$, IL-1 $\beta$, and IL-10 for D1M group. The predictive validities were quantified as the area under the ROC curves (c statistics).

\section{Results}

Table 1 indicates that the mean age of studied groups were as follows: control group (13.87 \pm 0.5 year) and T1DM group $(15.18 \pm 0.4$ year). Mean diabetes duration was $4.45 \pm$ 0.31 years in T1DM groups. There was a significant change in age and BMI in diabetic patients as compared with healthy group. It can be noted that the mean fasting blood glucose level was found to be elevated in T1D patients as compared to the healthy subjects. 
Table 1 Baseline characteristics of T1DM patients and control group

\begin{tabular}{llll}
\hline Variables & T1DM $(n=231)$ & Control $(n=168)$ & $P$ value \\
\hline Male/female & $110 / 121$ & $87 / 81$ & - \\
Age (years) & $15.18 \pm 0.389$ & $13.87 \pm 0.446$ & 0.029 \\
Duration (years) & $4.45 \pm 0.31$ & - & \\
Body mass index $\left(\mathrm{kg} / \mathrm{m}^{2}\right)$ & $23.9 \pm 0.77$ & $20.6 \pm 0.79$ & 0.004 \\
Waist Circumference (cm) & $75.5 \pm 1.6$ & $72 \pm 2.3$ & 0.22 \\
Hip Circumference (cm) & $87.2 \pm 1.6$ & $82.8 \pm 1.79$ & 0.079 \\
Waist/Hip Ratio & $0.86 \pm 0.01$ & $0.86 \pm 0.02$ & 0.9 \\
Fasting plasma glucose & $146.5 \pm 3.1$ & $85.2 \pm 2.3$ & 0.0001 \\
(FBG) (mg/dl) & & & \\
Insulin (mlU/ml) & $19.5 \pm 1.8$ & $16.6 \pm 1.3$ & 0.204 \\
\hline Num & & &
\end{tabular}

Numeric variables are described by mean \pm SE

$P$ values for comparison between T1DM and control groups. $P$ value $<0.05$ was considered as statistically significant

$P$ value in italics was considered as statistically significant

Table 2 and Fig. 1 summarize the levels of inflammatory markers (IL-1 $\alpha$, IL-1 $\beta$, and IL-10) in both T1D patients as well as control. The levels of IL- $1 \alpha, \mathrm{IL}-1 \beta$, and IL-10 were higher in the T1DM group than control.

The correlation between inflammatory cytokines (IL-1 $\alpha$, IL-1 $\beta$, and IL-10) and characteristic variables (age, duration, BMI, and insulin) in T1DM and controls are presented in Table 3.

The Roc analysis data obtained from receiver-operating characteristic (ROC) curve in (Table 4 and Fig. 2) was used to determine whether there was an additional benefit of using serum cytokines (IL-1 $\alpha$, IL-1 $\beta$, and IL-10) for predicting T1DM. The area under the curve (AUC) for IL10 was significantly higher than AUC for IL-1 $\alpha$ (AUC 0.865; 95\% CI 0.799-0.930) and IL-1 $\beta$ (AUC 0.776; 95\% CI 0.697-0.85) (Table 4 and Fig. 2). IL10 $>5.95$ predicted a T1DM with sensitivity and specificity of $96 \%$ and $90 \%$ respectively.

\section{Discussion}

Type 1 diabetes mellitus is a systemic disease causing abnormal fat, carbohydrate, and protein metabolism owing to insulin insufficiency (Poplawska-Kita et al. 2014). Insulin is one of the islet autoantigens responsible for the stimulation

Table 2 Serum levels of inflammatory cytokines in T1DM and control groups

\begin{tabular}{llll}
\hline Variables & $\begin{array}{l}\text { T1DM } \\
(n=231)\end{array}$ & $\begin{array}{l}\text { Control } \\
(n=168)\end{array}$ & $P$ value \\
\hline IL1-a (Pg/ml) & $0.76 \pm 0.03$ & $0.56 \pm 0.01$ & 0.0001 \\
IL $1-\beta(\mathrm{Pg} / \mathrm{ml})$ & $0.64 \pm 0.01$ & $0.52 \pm 0.01$ & 0.0001 \\
$\mathrm{IL}-10(\mathrm{Pg} / \mathrm{ml})$ & $8.2 \pm 0.21$ & $2.08 \pm 0.09$ & 0.0001
\end{tabular}

IL1- $\alpha$ interleukin 1-alpha, IL1- $\beta$ interleukin 1-beta, IL-10 interleukin 10 Data are presented as mean $\pm \mathrm{SE}$

$P$ value $<0.05$ was considered as statistically significant. $P$ value in italics was considered as statistically significant

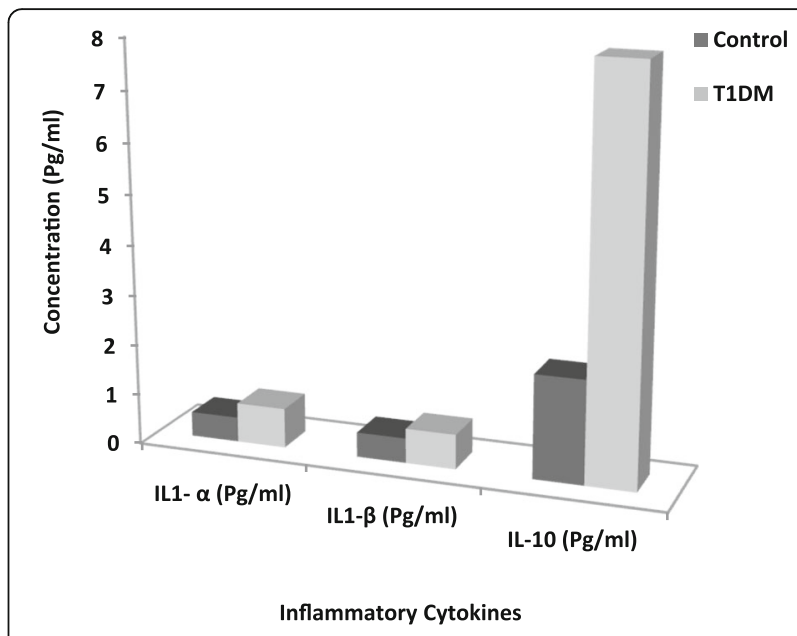

Fig. 1 Serum levels of inflammatory cytokines (IL-1a, IL-1 $\beta$, and IL-10) in T1DM and control

of T-lymphocyte functions, production of inflammatory cytokines, and T1DM progression (Tchorzewski et al. 2001). In T1DM, cells enhancing native and adaptive immunity infiltrate pancreatic islets, thus producing an abnormal inflammatory process known as insulitis recognized by autoreactive $\mathrm{T}$ cells and pathological autoantibody production (Bailey-Bucktrout et al. 2013). In cooperation within filtrating innate immune cells that release elevated concentrations of IL- $1 \alpha$ and IL-1 $\beta$, effectors T cells generate $\beta$-cells damage (Baumann et al. 2012). The pro-inflammatory cytokines serve in disease strength, while anti-inflammatory cytokines act to delay inflammation and support healing (Dinarello 2007).

In the present study, our data revealed that serum cytokine IL-1 $\alpha$ level was significantly higher in T1DM patients than control subjects. This result is in agreement with previous investigators who demonstrated an elevated activity of inflammation in T1D patients because of hyperglycemia and advanced glycation end products construction. Furthermore, Ozer et al. 2003 indicated that the pro-inflammatory cytokines IL- $1 \alpha$ and TNF- $\alpha$ could act essential roles alone or in combination in T1D pathogenesis (Glowinska and Urban 2003; Wasmuth et al. 2004; Dandona et al. 2004).

The pro-inflammatory cytokine IL-1 $\beta$ showed higher serum level in T1D patients compared to controls. This result is in the same line with Sesterheim et al. (2007) who observed that this cytokine serve in an autoimmune damage of pancreatic $\beta$-cells which favor the process of autoimmune and inflammatory response typical of T1D. Furthermore, our results are in accordance with results obtained by Dogan et al. (2006) who detected high concentrations of inflammatory markers in recently diagnosed T1D patients, what suggests that systemic inflammation is contributed to the onset of the disease. However, the level of this marker is known to stay high 
Table 3 Correlation between inflammatory cytokines and clinical and biochemical variables in T1DM patients and controls

\begin{tabular}{|c|c|c|c|c|c|c|c|c|c|}
\hline \multirow[t]{2}{*}{ Variables } & & \multicolumn{4}{|l|}{ T1DM } & \multicolumn{4}{|l|}{ Controls } \\
\hline & & BMl & IL-1a (Pg/ml) & $\mathrm{IL}-1 \beta(\mathrm{Pg} / \mathrm{ml})$ & IL-10 (pg/ml) & $\mathrm{BMl}$ & $\mathrm{IL}-1 \mathrm{a}(\mathrm{Pg} / \mathrm{ml})$ & $\mathrm{IL}-1 \beta(\mathrm{Pg} / \mathrm{ml})$ & $\mathrm{IL}-10(\mathrm{pg} / \mathrm{ml})$ \\
\hline \multirow[t]{2}{*}{ Age } & Pearson Correlation & $0.266^{*}$ & 0.031 & $0.248^{*}$ & -0.102 & $0.429^{* *}$ & 0.209 & 0.035 & 0.063 \\
\hline & $P$ value & 0.020 & 0.786 & 0.030 & 0.379 & 0.001 & 0.129 & 0.803 & 0.650 \\
\hline \multirow[t]{2}{*}{ Duration } & Pearson Correlation & -0.134 & -0.154 & -0.032 & -0.136 & - & - & - & - \\
\hline & $P$ value & 0.244 & 0.181 & 0.782 & 0.240 & & & & \\
\hline \multirow[t]{2}{*}{ BMl } & Pearson Correlation & 1 & 0.048 & -0.073 & 0.066 & 1 & 0.115 & -0.025 & -0.007 \\
\hline & $P$ value & & 0.677 & 0.530 & 0.567 & & 0.410 & 0.856 & 0.960 \\
\hline \multirow[t]{2}{*}{ Insulin (mlU/ml) } & Pearson Correlation & 0.020 & -0.042 & $0.408^{* *}$ & 0.007 & 0.070 & -0.042 & 0.211 & -0.042 \\
\hline & $P$ value & 0.862 & 0.718 & 0.000 & 0.949 & 0.616 & 0.761 & 0.126 & 0.762 \\
\hline \multirow[t]{2}{*}{ IL-1a (Pg/ml) } & Pearson Correlation & 0.048 & 1 & 0.210 & 0.109 & 0.115 & 1 & $0.580^{* *}$ & -0.097 \\
\hline & $P$ value & 0.677 & & 0.066 & 0.347 & 0.410 & & 0.000 & 0.486 \\
\hline \multirow[t]{2}{*}{$\mathrm{IL}-1 \beta(\mathrm{Pg} / \mathrm{ml})$} & Pearson Correlation & -0.073 & 0.210 & 1 & -0.088 & -0.025 & $0.580^{* *}$ & 1 & 0.074 \\
\hline & $P$ value & 0.530 & 0.066 & & 0.447 & -0.856 & 0.000 & & 0.597 \\
\hline \multirow[t]{2}{*}{ |L-10 (pg/ml) } & Pearson Correlation & 0.066 & 0.109 & -0.088 & 1 & -0.007 & -0.097 & 0.074 & 1 \\
\hline & $P$ value & 0.567 & 0.347 & 0.447 & & 0.960 & 0.486 & 0.597 & \\
\hline
\end{tabular}

*Correlation is significant at the 0.05 level

${ }^{* *}$ Correlation is significant at the 0.01 level

$P$ value in italics was considered as statistically significant

during DM progression, and it can probably relate to the development of complications.

Our findings showed that there was a significant increase of serum IL-10 level in diabetic patients as compared to controls. These results are consistent with a study performed by Reis et al. (2012), and He et al. (2014) demonstrated that the elevated levels of IL-10 in T1DM patients may be due to the production from a compensatory mechanism to the rise of pro-inflammatory cytokines. Regarding this purpose, the cytokines implicated in the pathogenesis of T1DM are essential for the progress of the disease, acting both in the positive control (pro-inflammatory cytokines) and in the negative control (anti-inflammatory cytokines) of the inflammation, and they can act in a cascade or alone. Also, Urcelay et al. (2004) demonstrated that IL-10 is an anti-inflammatory cytokine that appears to act trying to prevent DM development.

In our study, cytokine levels did not present correlations with each other. A probable reason for this fact is that the high levels of these inflammatory mediators appear primarily at the local level, through the advance of DM complication showing a systemic slight raise in blood flow in diabetic patients (Cardoso et al. 2017). On the other hand, a correlation was observed between the pro-inflammatory cytokines (IL-1 $\alpha$ and IL-1 $\beta$ ) that is important in the pathogenesis of insulin-dependent diabetes mellitus (Alexandraki et al. 2008). So, El-Mohamady et al. (2009) confirmed the principle that IL-1 antagonism has therapeutic potential in the management of DM, but they recommended that autoimmune constituent of T1DM might require therapeutic combination (e.g., with anti-CD3 antibodies). Additionally, He et al. (2014) noticed that the levels of cytokines (IL-1 and IL-10) were accomplished and they noticed the higher levels of cytokines in diabetic children as compared to controls.

Our data revealed that insulin was positively associated with IL-1 $\beta$.Similar outcomes were achieved by previous study of Pérez-Marín et al. (2015) who detect elevated concentration of IL-1 $\beta$ in early diagnosed children with diabetes. So, Molloul et al. (2010) proposed that suppression of cytokine induced $\beta$-cells destruction may be a possible current approach for $\beta$-cell protection. Regarding age, our study reported a positive correlation with both of BMI and IL-1 $\beta$ which are in consistent with other investigations who stated that age-related decay of

Table 4 ROC analysis of inflammatory cytokines in T1DM and controls

\begin{tabular}{llllllll}
\hline Parameters & Cut-off & AUC & \pm SE & Sensitivity \% & Specificity \% & $95 \% \mathrm{Cl}$ & $P$ value \\
\hline IL-1a $(\mathrm{pg} / \mathrm{ml})$ & 0.615 & 0.865 & 0.033 & 87 & 80 & $0.799-0.930$ \\
$\mathrm{IL}-1 \beta(\mathrm{pg} / \mathrm{ml})$ & 0.545 & 0.776 & 0.040 & 70 & 67 & $0.697-0.856$ & 0.000 \\
$\mathrm{IL}-10(\mathrm{pg} / \mathrm{ml})$ & 5.95 & 0.995 & 0.004 & 96 & 90 & $0.986-1$ & 0.000 \\
\hline
\end{tabular}

AUC area under the curve, SE standard error, 95\% CI 95\% confidence interval for AUC

$P$ value $<0.05$ was considered as statistically significant

$P$ value in italics was considered as statistically significant 


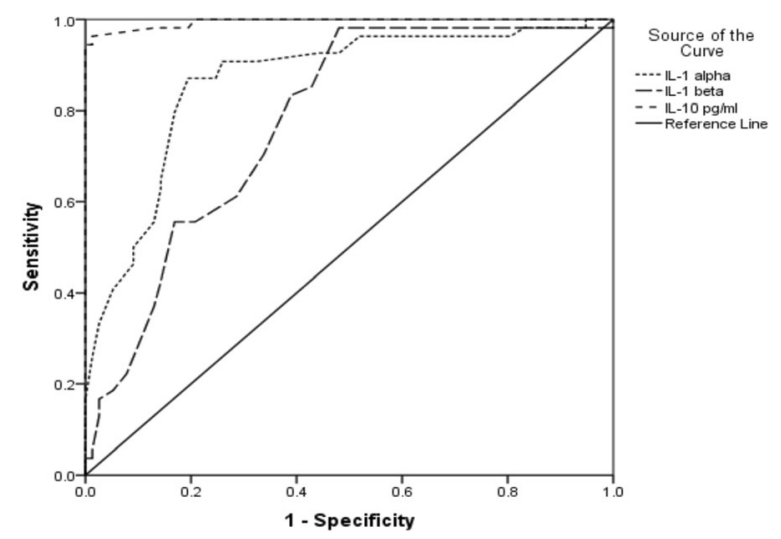

Fig. 2 ROC curve of inflammatory cytokines (IL1-a, IL1- $\beta$, and IL-10)

immune function owing to obesity, redox discrepancy, social stress, and chronic infections by pathogens are some of the aspects which prompt permanent irregulation and stimulation of the pro-inflammatory response (Vasto et al. 2007; Chung et al. 2009; Freund et al. 2010; Shaw et al. 2011; Danese and BS 2012; Li 2013). Such as, low-grade, chronic inflammation is induced by greater concentrations of pro-inflammatory proteins owing to an age-associated redox discrepancy that induces several pro-inflammatory signaling pathways (Chung et al. 2009; Xu et al. 2010).

In order to predict if the inflammatory cytokines (IL- $1 \alpha$, IL-1 $\beta$, and IL-10) were beneficial as biomarkers in early screening for T1DM and in monitoring immunological treatment, diagnostic reliability was determined to select the best cut-off value within the patient group (calculated from the control group). Our data revealed that IL10 was the best to discriminate T1DM with cut-off value of $5.95 \mathrm{pg} / \mathrm{ml}$ and, at this value, the sensitivity was $96 \%$ and specificity was $90 \%$. The next most useful test was IL- $1 \alpha$ and its cut-off value of $0.615 \mathrm{pg} / \mathrm{ml}$ at which the sensitivity was $87 \%$ and specificity was $80 \%$. Finally, the last one was IL- $1 \beta$ with cut-off value of $0.545 \mathrm{pg} / \mathrm{ml}$, which had the lowest sensitivity and specificity (70\% and $67 \%$, respectively).

\section{Conclusions}

We conclude that circulating levels of IL- $1 \alpha$, IL- $1 \beta$, and IL-10 were highly significant in type 1 diabetic patients compared to healthy controls but their levels are not related to disease duration and body mass index. This is highly expressive of the convenience of these cytokines alone, or in combination to support in further investigative type 1 diabetes pathophysiology and monitoring pharmacological interventions to interpose with the progress and evolution of diabetes.

\section{Limitations}

Our study had some limitations; first of all, it was a retrospective study. Secondly, the patients, in whom autoimmune diseases (e.g., rheumatoid arthritis); steroid therapy and macrovascular complications (e.g., myocardial infarction); any diabetic complications such as nephropathy, neuropathy, or retinopathy; and acute or chronic diseases were excluded, which mean that there was a potential bias in the selection of the study subjects.

Future larger scale prospective studies are required to confirm the correlations and predict the value of more pro-inflammatory and anti-inflammatory serum levels within patients with T1DM.

\section{Acknowledgements}

We thank attendants and parents for their participation and kind assistance.

\section{Funding}

This study was supported by project grants from the National Research Center (Project \#. 10010205).

Availability of data and materials

The datasets supporting the results are included within the article.

\section{Authors' contributions}

EA, SA, and MA conceived and designed the study and are responsible for the facility in which the study is conducted. WG and LM performed the experiments. EA, WG, and LM analyzed the data. EA, WG, and LM contributed the reagent. All authors wrote the first draft of the manuscript, the statistical analysis, and interpretation of the data. EA, WG, and LM contributed to the original data collection. All the authors have accepted responsibility for the entire content of this submitted manuscript and approved submission. All authors have read the final manuscript, revised it, and agreed that the work is ready for publication.

\section{Ethics approval and consent to participate}

It is a cross-sectional observational study done after obtaining approval from the ethical committee of the National Research Centre, Cairo, Egypt (registration number is 17-033)

\section{Consent for publication}

Written informed consent was obtained from all patients and controls or their parents after full discussion about the aim of the study and for publication including consequences that may result. The patients involved signed an informed consent prior to commencement of the study.

\section{Competing interests}

The authors declare that they have no competing interests.

\section{Publisher's Note}

Springer Nature remains neutral with regard to jurisdictional claims in published maps and institutional affiliations.

\section{Author details}

${ }^{1}$ Biochemistry Department, National Research Centre, Giza, Egypt. ${ }^{2}$ Pediatric Department, National Research Centre, Giza, Egypt.

Received: 7 June 2018 Accepted: 8 October 2018

Published online: 23 October 2018

\section{References}

Alexandraki KI, Piperi C, Ziakas PD, Apostolopoulos NV, Makrilakis K, Syriou V, et al. Cytokine secretion in long-standing diabetes mellitus type 1 and 2 : associations with low-grade systemic inflammation. J clin immunol 2008; 28(4):314-321. Epub2008/01/29. https://doi.org/10.1007/s10875-007-9164-1 PMID: 18224429

Al-Terehi M, Ghaleb R, Al-Oubaidy SA, Al-Saadi AH, Zaidan HK (2016) Study TNF-a gene polymorphism in type 1 diabetic patients using amplification refectory mutation system (ARMS) technique. J Chem Pharm Sci 9(3):1107-1110 
Bailey-Bucktrout SL, Martinez-Llordella M, Zhou X, Anthony B, Rosenthal W, Luche $\mathrm{H}$ et al (2013) Selfantigen-driven activation induces instability of regulatory $T$ cells during an inflammatory autoimmune response. Immunity 39(5):949-962

Banerjee M, Saxena M (2014) Genetic polymorphisms of cytokine genes in type 2 diabetes mellitus. World J Diabetes 5:493-504

Baumann B, Salem HH, Boehm BO (2012) Anti-inflammatory therapy in type 1 diabetes. Curr Diab Rep 12(5):499-509

Buraczynska M, Ksiazek P, Baranowicz-Gaszczyk I, Jozwiak L (2007) Association of the VEGF gene polymorphism with diabetic retinopathy in type 2 diabetes patients. Nephrol Dial Transplant 22:827-832

Cameron N (1986) The methods of auxological anthropology. In: Falkner F, Tanner JM (eds) Human growth 3 methodology. Plenum Press, New York, pp 3-46

Cardoso JF, Gomes KB, Fernandes AP, Domingueti CP (2017) Evaluation of cytokines in type 1 diabetes patients with and without retinopathy. J Bras Patol Med Lab 53(1):31-37

Chung HY, Cesari M, Anton S, Marzetti E, Giovannini S et al (2009) Molecular inflammation: underpinnings of aging and age-related diseases. Ageing Res Rev 8:18-30

Dabelea D, Mayer-Davis EJ, Saydah S, Imperatore G, LinderB, Divers J, Bell R, et al. Prevalence of type 1 and type 2 diabetes among children andadolescents from 2001 to 2009. JAMA 2014; 311: 1778-1786. [PMID:24794371 DOI: https://doi.org/10.1001/jama.2014.3201

Dandona P, Aljada A, Bandyopadhyay A (2004) Inflammation: the link between insulin resistance, obesity and diabetes. Trends Immunol 25:4-7

Danese A, BS ME (2012) Adverse childhood experiences, allostasis, allostatic load, and age-related disease. Physiol Behav 106:29-39

Dinarello CA (2007) Historical insights into cytokines. Eur J Immunol 37(Suppl 1):S34-S45

Dinarello CA, Simon A, van der Meer JW (2012) Treating inflammation by blocking interleukin-1 in a broad spectrum of diseases. Nat Rev Drug Disc 11:633-652

Dogan Y, Akarsu S, Ustundag B, Yilmaz E, Gurgoze MK. Serum IL-1 beta, IL-2, and IL-6 in insulin-dependent diabetic children. Mediat Inflamm 2006; 2006(1): 29206. Article ID 59201): 29206, Pages 1-6 DOl https://doi.org/10.1155/MI/ 2006/59206

El-Mohamady I, Haron M, Rashed L, Halawa E, Badawy N, AndSediek H (2009) Cytokines in Egyptian children with type 1 diabetes. Med J Cairo Univ 77(4):191-196

Freund A, Orjalo AV, Desprez PY, Campisi J (2010) Inflammatory networks during cellular senescence: causes and consequences. Trends Mol Med 16:238-246

Galtier F (2010) Definition, epidemiology, risk factors. Diabetes Metab 36:628-651. 21163426. https://doi.org/10.1016/ j.diabet.2010.11.014

Glowinska B, Urban M. Selected cytokines (IL-6, IL-8, IL-10, MCP-1, TNF- alpha) in children and adolescents with atherosclerosis risk factors: obesity, hypertension, diabetes. Wiad Lek 2003; 3; 56 (3-4): 109-116

He JS, Xie PS, Luo DS, Sun CJ, Zhang YG, Liu FX (2014) Role of immune dysfunction in pathogenesis of type 1 diabetes mellitus in children. Asian Pac J Trop Med 7(10):823-826

International Diabetes Federation. IDF Diabetes Atlas. 7th edition. Brussels, Belgium: International Diabetes Federation; 2015

Kolla VK, Madhavi G, Pulla Reddy B, Srikanth Babu BM, Yashovanthi J, Valluri VL et al (2009) Association of tumor necrosis factor alpha, interferon gamma and IL-10 gene polymorphisms with peripheral neuropathy in south Indian patients with type 2 DM. Arch Med Res 40(4):276-284

Li W (2013) Phagocyte dysfunction, tissue aging and degeneration. Ageing Res Rev 12:1005-1012

M S, DR M (2014) Inflammation and diabetes. Inter Discip J Microinflammation 1: 1. https://doi.org/10.4172/ijm.1000110

Molloul MB, Cheeran MC, Hu S, Little MR, Lokensgard JR (2010) Excess neutrophil infiltration during cytomegalovirus brain infection of interleukin-10- deficient mice. J Neuroimmunol 227:101-110

Moore KW, de Waal Malefyt R, Coffman RL, O'Garra A (2001) Interleukin-10 and the interleukin-10 receptor. Annu Rev Immunol 19:683-665

Navarro-González FJ, Mora-Fernández C (2008) The role of inflammatory cytokines in diabetic nephropathy. J Am Soc Nephrol 19(3):433-442

Ozer G, Teker Z, Cetiner S, Yilmaz M, Topaloglu AK, Onenli-Mungan N et al (2003) Serum IL-1, IL-2, TNF-alpha and INF-gamma levels of patients with type 1 diabetes mellitus andtheir siblings. J Pediatr Endocrinol Metab 16(2):203-210

Pérez-Marín M, Gómez-Rico I, Montoya-Castilla I (2015) Type 1 diabetes mellitus: psychosocial factors and adjustment of the pediatric patient and his/her family. Review. Arch Argent Pediatr 113(2):158-162

Poplawska-Kita A, Siewko K, Szpak P, Krol B, Telejko B, Klimiuk PA et al (2014) Association between type 1diabetes and periodontal health. Adv Med Sci 59(1):126-131. 24797988. https://doi.org/10.1016/j.advms.2014.01.002
Reis JS, Amaral CAV, Valp CMO, Fernandes JS, Borges EA, Isoni CA et al (2012) Oxidative stress and interleukin-6secretion during the progression of type 1 diabetes. Arq Bras Endocrinol Metab 56(7):56-57

Sesterheim P, Saitovitch D, Staub HL (2007) Diabetes mellitus tipo 1:multifatores que conferem suscetibilidade à patogenia auto-imune. Sci Med 17(4):212-217

Shaw AC, Panda A, Joshi SR, Qian F, Allore HG et al (2011) Dysregulation of human Toll-like receptor function in aging. Ageing Res Rev 10:346-353

Tanner JM, Hiernaux J, Jarman S (1969) Growth and physical studies. In: Weiner JS, Lourie JA (eds) Human biology: a guide to field methods. Blackwell Scientific Publ, Oxford, pp 3-41

Tchorzewski H, Glowacka E, Banasik M et al (2001) Activated lymphocytes from patients with high risk of type I diabetes mellitus have different ability to produce interferon- gamma, interleukin 6 and interleukin 10 and undergo anti CD95 induced apoptosis after insulin stimulation. Immunol Lett 75(3):225-234

Urcelay E, Santiago JL, de la Calle H, Martínez A, Figueredo A, Fernández-Arquero $M$ et al (2004) Interleukin-10 polymorphisms in Spanish type 1 diabetes patients. Genes Immun 5:306-309

Vasto S, Candore G, Balistreri CR, Caruso M, Colonna-Romano G et al (2007) Inflammatory networks in ageing, age-related diseases and longevity. Mech Ageing Dev 128:83-91

Wasmuth HE, Kunz D, Graf J, Stanzel S, Purucker EA, Koch A et al (2004) Hyperglycemia at admission to the intensive care unit is associated with elevated serum concentrations of interleukin- 6 and reduced ex vivo secretion of tumor M: genetic and clinical implications. Diabetes 44:863-870

Xu J, Marzetti E, Seo AY, Kim J-S, Prolla TA et al (2010) The emerging role of iron dyshomeostasis in the mitochondrial decay of aging. Mech Ageing Dev 131:487-493

\section{Submit your manuscript to a SpringerOpen ${ }^{\circ}$ journal and benefit from:}

- Convenient online submission

- Rigorous peer review

- Open access: articles freely available online

High visibility within the field

- Retaining the copyright to your article

Submit your next manuscript at $>$ springeropen.com 